\title{
Integrated Analysis of Gene Copy Number, Copy Neutral LOH, and microRNA Profiles in Adult Acute Lymphoblastic Leukemia
}

\author{
S. Ninomiya ${ }^{a} \quad$ A. Tyybäkinoja ${ }^{a} \quad$ I. Borze $^{a} \quad$ R. Räty ${ }^{b} \quad$ U.M. Saarinen-Pihkalac \\ A. Usvasalo ${ }^{c} \quad$ E. Elonen ${ }^{b} \quad$ S. Knuutila ${ }^{a}$ \\ ${ }^{a}$ Department of Pathology, HUSLAB and University of Helsinki, ${ }^{b}$ Department of Hematology, Helsinki \\ University Central Hospital, and ${ }^{\mathrm{C} H o s p i t a l}$ for Children and Adolescents, University of Helsinki, Helsinki, Finland
}

\section{Key Words}

$\mathrm{ALL} \cdot$ Array $\mathrm{CGH} \cdot B C R-A B L 1 \cdot$ Copy number alteration • miRNA $\cdot$ SNP array

\begin{abstract}
We adopted an integrated analysis of gene copy number alterations (CNAs), copy number neutral loss of heterozygosity (CNN LOH), and microRNA (miRNA) profiling in 21 adult acute lymphoblastic leukemia (ALL) patients. This study revealed the most frequent CNAs to be at chromosomes 9p, 7, and 17 and recurrent CNN LOH at 5p, 9p, and Xq. As for the most differentially expressed miRNAs, they included 8 upregulated and 14 downregulated miRNAs, of which miR-148a at 7p15.2, miR-22 at 17p13.3, miR-223 at Xq12, as well as miR-101-2 at 9p24.1 exhibited recurrent CNAs or CNN LOH. miR-101-2 was recurrently downregulated, and although the related CNN $\mathrm{LOH}$ was detected only in BCR-ABL1 negative cases (2/14), deletions of miR-101-2 were observed solely in BCR-ABL1 positive cases (4/7). Finally, $B C R-A B L 1$ positive cases, in contrast to negative ones, were characterized by slightly, but still significantly, higher expression levels of miR-29b.
\end{abstract}

Copyright $\odot 2012$ S. Karger AG, Basel

S.N. and A.T. contributed equally to this work.
Knowledge of various genetic and epigenetic alterations in acute lymphoblastic leukemia (ALL) has enhanced the categorization of patients into prognostic groups and has been one of the factors leading to improved (over 80\%) cure rates in children [Armstrong and Look, 2005; Pui and Evans, 2006]. In adult ALL, the outcome is, nevertheless, significantly worse even today, with a cure rate of only 30-40\% [Pui and Evans, 2006]. This is, at least partly, due to the higher frequency of unfavorable genetic alterations in adults, for example $t(4 ; 11)$, $\mathrm{t}(8 ; 14)$, complex karyotypes, low hypodiploidy, near triploidy, as well as, importantly, $\mathrm{t}(9 ; 22)$ resulting in the formation of $B C R-A B L 1$ fusion genes [Moorman et al., 2010]. Indeed, the incidence of $B C R-A B L 1$ with an adverse prognosis increases with age; it is detected only in $3-5 \%$ of childhood patients but in as many as $20-40 \%$ of adult patients [Dombret et al., 2002; Armstrong and Look, 2005; Pui and Evans, 2006; Moorman et al., 2010]. Whereas targeted treatment with tyrosine kinase inhibitors has considerably improved the outcome of $B C R-A B L 1$ positive chronic myeloid leukemia (CML), such good response rates could so far not be reached in $B C R-A B L 1$ positive ALL patients [Armstrong and Look, 2005; Fullmer et al., 2011].

In recent years, high-resolution genome-wide array comparative genomic hybridization (aCGH) and singlenucleotide polymorphism (SNP) microarray analyses 
have improved the detection of copy number alterations (CNAs) and regions exhibiting loss of heterozygosity (LOH) also in ALL [Irving et al., 2005; Kuiper et al., 2007; Mullighan et al., 2007; Strefford et al., 2007; Kuchinskaya et al., 2008; Usvasalo et al., 2008; Bungaro et al., 2009; Usvasalo et al., 2009, 2010a, b; Simons et al., 2011]. Another important advancement has been the discovery of microRNAs (miRNAs), small (19-25 nucleotides) noncoding RNAs involved in the regulation of mRNA translation. miRNAs, which may have either tumor suppressor or oncogene function, may act as promising therapeutic targets and, moreover, may be used in cancer classification [Lu et al., 2005; Croce, 2009]. Previous studies have indeed revealed deregulated miRNA expression profiles that help in differentiating ALL from other cancers and from normal cells as well as in specifying cytogenetic subgroups [Lu et al., 2005; Mi et al., 2007].

However, more detailed information on the molecular mechanisms behind adult ALL is essential in order to discover novel prognostic and predictive biomarkers and to develop targeted therapies for this disease. Hence, we performed gene copy number, $\mathrm{LOH}$, and miRNA expression analyses using high-resolution oligonucleotide microarrays.

\section{Material and Methods}

\section{Patients and Controls}

A total of 21 ALL patients $>25$ years of age at diagnosis, who were diagnosed and treated at the Helsinki University Central Hospital, were included in this study. They all fulfilled the FAB classification criteria F1. DNA extracted from frozen bone marrow samples was used for aCGH and SNP array analyses, whereas RNAs for miRNA expression analyses were extracted from archival formalin-fixed paraffin-embedded (FFPE) bone marrow core biopsy samples as described before [Borze et al., 2011]. Control DNA for aCGH was derived from 4 pooled sex-matched peripheral blood samples of healthy donors, while for miRNA experiments, miRNAs from 8 different bone marrow aspirate smears from healthy bone marrow donors were used as controls. The study was approved by the Local Institutional Review Board and the National Authority for Medicolegal Affairs. Some of the copy number data obtained by aCGH (all 21 cases) and SNP array (7 cases) have been published previously [Usvasalo et al., 2010a, b].

\section{K Array Comparative Genomic Hybridization}

The copy number analysis was performed using the Agilent 244K (Agilent Technologies, Santa Clara, Calif., USA) CGH microarrays on 21 adult ALL samples as previously described [Usvasalo et al., 2010a]. In brief, DNA digestion, labeling, hybridization, and washing of slides were performed according to the manufacturer's protocols (version 4.0). The slides were scanned using the Agilent's microarray scanner G2565AA (Agilent Technologies). The images were analyzed with the Agilent Feature Extraction software (version 9.5.3.1), and the data were analyzed with the Genomic workbench Standard Edition (version 5.0.14) with the ADM-2 Algorithm.

\section{SNP 6.0 Microarray Analysis}

All samples were analyzed with Affymetrix Genome-Wide Human 6.0 SNP arrays (Affymetrix, Santa Clara, Calif., USA) according to the manufacturer's instructions as described before [Usvasalo et al., 2010a]. In brief, 250 ng aliquots of genomic DNA were digested with NspI and StyI (NEB, Hitchin, Herts, UK) in separate reactions. The digested DNA was ligated using a corresponding adaptor and next, each reaction was PCR-amplified using a common PCR primer 002 (Affymetrix). Purified PCR products were fragmented using a fragmentation reagent and then labeled using DNA labeling reagents (Affymetrix). The labeled DNA was subsequently hybridized to Genome-Wide-Human SNP Array 6.0. Washing and staining were performed on the GeneChip ${ }^{\circledR}$ Fluidics Station 450 (Affymetrix), while arrays were scanned using the GeneChip ${ }^{\circledR}$ Scanner $30007 \mathrm{G}$ (Affymetrix). Due to poor quality, 1 of the 21 samples was excluded. Copy number alterations and copy neutral $\mathrm{LOH}$ were analyzed with the Genotyping Console 3.0.2 (Affymetrix) and the Chromosome Analysis Suite 1.0.1 (ChAS, Affymetrix). We used a dataset of 90 Caucasian individuals studied in the International HapMap Project (www.hapmap.org) as a reference set for the analysis and regarded $\mathrm{LOH}$ regions $>5 \mathrm{Mb}$ defined by at least 10 adjacent probes as significant.

\section{miRNA Expression}

The miRNA expression analysis was performed on 19/21 adult ALL cases using the Agilent Human miRNA (V3) microarrays containing 866 human and 89 human viral miRNA probes from the Sanger database v12.0 (Agilent Technologies). miRNA was extracted from FFPE bone marrow core biopsy samples applying the miRNeasy FFPE Kit (Qiagen, Valencia, Calif., USA). The use of FFPE core biopsy sample material in miRNA microarray analysis has previously been validated in our laboratory [Borze et al., 2011]. In addition to ALL samples, the miRNA expression analysis was performed on 8 normal bone marrow aspirate smear slide samples that were obtained from healthy bone marrow donors and extracted using the miRNeasy Mini kit (Qiagen).

The miRNA quality and quantity were analyzed with the NanoDrop ND-1000 Spectrophotometer (NanoDrop Technologies, Inc., Del., USA) and the Agilent 2100 Bioanalyzer (Agilent Technologies). Samples (100 ng) were labeled and hybridized to microarrays according to the manufacturer's protocol (v.2.1) after which microarrays were scanned with the Agilent microarray scanner (G2539A) and data extracted from images with the Feature Extraction Software v. 9.5 (Agilent Technologies).

Duplicate experiments were performed on 4 out of 19 samples to verify reproducibility of the experiments and analyzed using the GeneSpring GX 10.0.2 correlation coefficient test (Agilent Technologies). The data analysis was then done using the Chipster software (v1.4.4) (http://chipster.csc.fi/) with default values set for Agilent miRNA arrays. The background was subtracted using normexp with the background offset 50 , while data were normalized with quantile normalization and control probes were removed. Subsequently, data were filtered using the coefficient of variation and a threshold of 0.5 to filter out the least variable miRNAs. miRNA expression between 8 normal controls and ALL 
Table 1. Clinical characteristics, karyotype, and aCGH and SNP array results of the patients in the study

\begin{tabular}{|c|c|c|c|c|c|}
\hline Patient & $\begin{array}{l}\text { Sex/ } \\
\text { age }\end{array}$ & $\begin{array}{l}\text { ALL } \\
\text { type }\end{array}$ & Karyotype & CNA (aCGH, SNP array) ${ }^{a}$ & CNN LOH \\
\hline AA201 & $\mathrm{M} / 49$ & B & $46, \mathrm{XY}, \operatorname{del}(9)(\mathrm{p} 21)$ & $\begin{array}{l}\operatorname{dim}(3 q 13.2,9 p 13.1 p 22.1,12 q 21.33,15 q 21.3 \\
16 q 22.1)\end{array}$ & $1 \mathrm{p} 32.3 \mathrm{p} 33,5 \mathrm{p} 12 \mathrm{p} 13.2$ \\
\hline$\overline{\mathrm{AA} 202}$ & $\mathrm{M} / 41$ & $\mathrm{~T}$ & $47, \mathrm{XY},+$ mar & $\begin{array}{l}\text { enh(1q23.3qter, 3q26.33qter, 17p11.2); } \\
\operatorname{dim}(17 \mathrm{p} 11.2 \text { pter })\end{array}$ & \\
\hline AA203 & $\mathrm{F} / 50$ & B & $46, \mathrm{XX},(\mathrm{t} 9 ; 22)(\mathrm{q} 34 ; \mathrm{q} 11)$ & $\operatorname{dim}(6 p 22.3,9 p, 9 q 12 q 34.3,15 q 15.1,17 q 22)$ & \\
\hline AA206 & $\mathrm{M} / 39$ & B & $46, \mathrm{XY},(4 ; 11)(\mathrm{q} 21 ; \mathrm{q} 23)$ & & \\
\hline AA207 & $\mathrm{M} / 50$ & B & $\begin{array}{l}\text { 46,XY,del }(6 \mathrm{q}), \text { add }(14)(\mathrm{q} 32) \times 2, \mathrm{t}(9 ; 22) \\
(\mathrm{q} 34 ; \mathrm{q} 11) / 46, \mathrm{XY}\end{array}$ & $\begin{array}{l}\text { enh(9q34.12qter, 22q11.1q11.23); dim(7, 9p22.3p23, } \\
\text { 9p21.2p21.3, 11p12p14.1, 16q12.1qter) }\end{array}$ & \\
\hline AA208 & $\mathrm{F} / 44$ & B & $46, \mathrm{XX}$ & $\operatorname{dim}(7 \mathbf{p} 11.2 \mathrm{p} 13)$ & Xq11.1q13.1 \\
\hline AA210 & $\mathrm{M} / 49$ & B & $47, \mathrm{XY}, \mathrm{t}(4 ; 11)(\mathrm{q} 21 ; \mathrm{q} 23),+8 / 46, \mathrm{XY}$ & $\operatorname{enh}(11 \mathrm{q} 23.3) ; \operatorname{dim}(\mathbf{3 q} 26.33,9 \mathrm{p} 21.3)$ & \\
\hline AA214 & $\mathrm{M} / 27$ & $\mathrm{~T}$ & 40-43,XY,der(10)t(10;17),inc/79-89,idem & enh(17q12qter); dim(10p15.1pter, 15q, 17q11.2) & $\begin{array}{l}\text { 6pcenp12.1, 6q11.1q12, } \\
\text { 9p13.3p24.3 }\end{array}$ \\
\hline$\overline{\mathrm{AA} 215}$ & $\mathrm{M} / 45$ & B & 46,XY/46,XY,t(5;16)(p?;q?) & $\operatorname{enh}(8 \mathrm{q} 24.13 q$ ter, 15q26.1); $\operatorname{dim}(7 \mathrm{p} 12.1 \mathrm{p} 14.1)$ & $\begin{array}{l}\text { 1p12p22.1, 1q21.1q21.3, } \\
\text { 9p21.1p22.3, 9q13q21.2, } \\
\text { 11pcenp14.1, 11pcenq21, } \\
\text { 12p11.21p12.3, 13q13.3q14.11, } \\
\text { 14q32.2q32.33, 18q21.1q21.2 }\end{array}$ \\
\hline AA216 & $\mathrm{M} / 26$ & B & $\begin{array}{l}\text { 46,XY,-9,t(9;22)(q34;q11),+r(?),mar, } \\
\text { inc/63-65,idem } / 46, \mathrm{XY}\end{array}$ & $\operatorname{dim}(1 \mathrm{p} 36.23,7 \mathrm{p} 12.2,7 \mathrm{p} 14.1,9 \mathrm{p}, 11 \mathrm{p} 13,12 \mathrm{q} 21.33)$ & \\
\hline AA217 & $\mathrm{M} / 43$ & $\mathrm{~T}$ & $47, \mathrm{XY},+4, \operatorname{del}(5 \mathrm{q})[7] / 46, \mathrm{XY}[4]$ & $\operatorname{enh}(4) ; \operatorname{dim}(5 q 14.3 q 31.3)$ & $6 \mathrm{p} 21.33 \mathrm{p} 25.3$ \\
\hline AA218 & $\mathrm{F} / 63$ & B & $\begin{array}{l}44-49, \mathrm{XX}, \mathrm{t}(9 ; 22)(\mathrm{q} 34 ; \mathrm{q} 11),+2 \text { mar,inc }[3] \\
/ 46, \mathrm{XX}[18]\end{array}$ & $\operatorname{dim}(7, \mathbf{1 1 q 2 3 . 3})$ & Xq11.1q13.1, Xq13.1q21.1 \\
\hline$\overline{\mathrm{AA} 224}$ & $\mathrm{~F} / 65$ & $\mathrm{~B}$ & $46, \mathrm{XX}$ & $\operatorname{enh}(8) ; \operatorname{dim}(7 \mathrm{p} 12.2,9 \mathrm{p} 22.3 \mathrm{p} 23,9 \mathrm{p} 21.1 \mathrm{p} 22.1)$ & 4p12p13, Xq13.1q21.1 \\
\hline
\end{tabular}

${ }^{a}$ Aberrations in italics: detected only with SNP array; aberrations in bold: detected only with $244 \mathrm{~K}$ aCGH; enh = enhanced copy number; dim = reduced copy number.

samples was compared using the empirical Bayes test [Smyth, 2004 ] and the Benjamini-Hochberg (BH) multiple testing correction. The same test statistics were used to compare the miRNA expression differences between $B C R-A B L 1$ positive and negative cases. The miRNAs were considered differentially expressed when they had a cut-off corrected $p$ value of $p<0.05$ and a fold change of $\leq 1$. Genomic locations were obtained for miRNAs according to genome build NCBI36. In each patient, CNAs and CNN LOH of differentially expressed miRNA loci were then analyzed.

Predicted target genes for the 22 most differentially expressed miRNAs in ALL were obtained using the Chipster's tools. Targets were retrieved from miRanda [Enright et al., 2003], PicTar [Krek et al., 2005], TargetScan [Lewis et al., 2005], and miRBase [Griffiths-
Jones et al., 2008]. A list of target genes present in all of these databases was created, and next, a pathway analysis was performed using the Hypergeometric test for ConsensusPathDB [Kamburov et al., 2009] with a p value threshold $p<0.05$. From the miRNA target lists the candidate tumor suppressors and oncogenes (e.g. BTLA, $C D K N 2 A$, and $M Y C$ ), earlier identified by the overlapping regions of losses or gains by using aCGH, were searched to assess whether the differentially expressed miRNAs were potential regulators of some of those genes. Pathway analyses were performed for miR$29 \mathrm{~b}$ and miR-101 target genes using the Chipster software.

The raw data for all 3 array types used in the present study are available at the CanGEM database (http://www.cangem.org) [Scheinin et al., 2008]. 


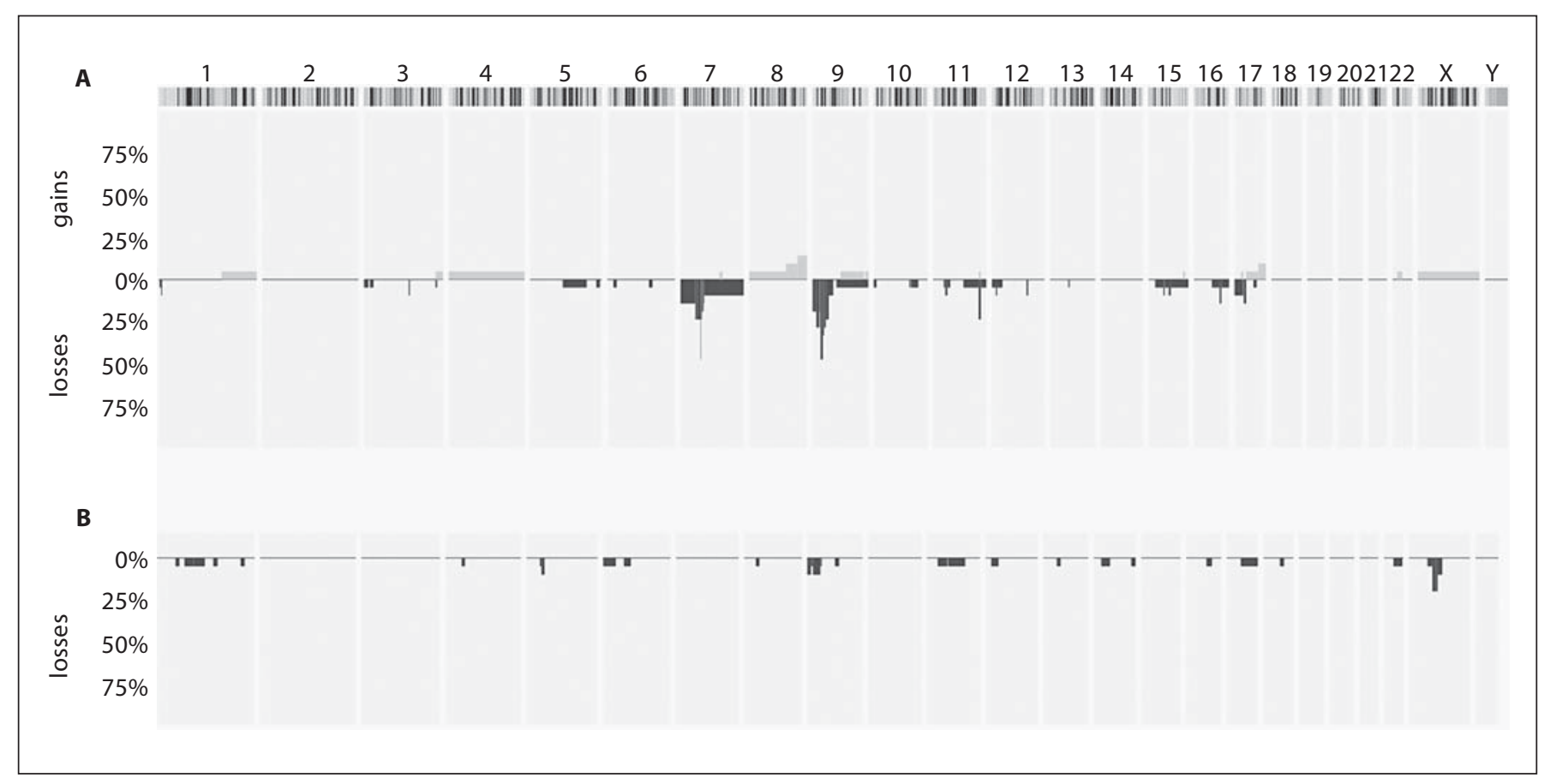

Fig. 1. Chromosomal alterations in adult ALL detected with aCGH and SNP array. A Copy number alterations. B Copy number neutral LOH. Figures have been prepared by using Progenetix online tools, www.progenetix. net [Baudis and Cleary, 2001].

\section{Results}

\section{Gene Copy Number Changes}

Copy number alterations (CNA) were detected in 19/21 (90\%) adult ALL patients using $244 \mathrm{~K}$ oligonucleotide aCGH and SNP array analyses (table 1, online suppl. table 1, www.karger.com/doi/10.1159/000337297), while alterations using conventional cytogenetics had been detected only in $15 / 21$ patients (71\%) (table 1). Importantly, similar copy number alterations were detected with the Affymetrix SNP 6.0 and with the Agilent $244 \mathrm{~K}$ arrays, with a few exceptions. Some small copy number losses at 3q26.33, 7p12.2, 11q23, and 10q23.33q25.1 were detected solely by the $244 \mathrm{~K}$ aCGH, whereas only the SNP array revealed a copy number loss at $6 \mathrm{p} 22.3$. In some cases, the $244 \mathrm{~K}$ array showed homozygous deletions of CDKN2A and $C D K N 2 B$, while the SNP array showed merely heterozygous copy number losses (table 1, online suppl. table 1).

The most common alteration, detected in 10/21 (45\%) cases, was a deletion of $9 \mathrm{p} 21.3$ containing the CDKN2A and $C D K N A 2 B$ genes. We also observed recurrent deletions of JAK2 at 9p24.1 (4/21 cases) and PAX5 at 9p13.2 (5/21 cases). Other recurrent alterations were deletions/ losses at chromosomes 1p, 3q, 7, 11q, 12, 15q, 16q, and 17p, as well as gains/amplifications at $8 \mathrm{q}$ and $17 \mathrm{q}$ (table 1, fig. 1A). These CNA regions included several candidate genes such as BTLA, RERE, IKZF1, DDC, MLL, MYC, TP53, TCF12, NF1, ETV6, BTG1, and E2F4.

Seven out of the 21 cases analyzed with the aCGH and/ or SNP array method were $B C R-A B L 1$ positive and $14 / 21$ were $B C R-A B L 1$ negative. IKZF1 deletions were detected in $6 / 7$ of $B C R-A B L 1$ positive cases and in $5 / 14$ of $B C R$ $A B L 1$ negative cases.

\section{Copy Number Neutral LOH}

With the Affymetrix SNP 6.0 arrays, LOH without copy number alterations and $>5 \mathrm{Mb}$ were detected in $12 / 20(60 \%)$ of the cases (table 1). Recurrent CNN LOH was observed at $5 \mathrm{p}(\mathrm{n}=2), 9 \mathrm{p}(\mathrm{n}=3)$, and Xq $(\mathrm{n}=5)(\mathrm{ta}-$ ble 1, fig. 1B).

\section{miRNA Expression}

Expression differences between ALL $(n=19)$ and 8 normal control samples were tested, and 22 differentially expressed miRNAs (8 upregulated and 14 downregulated) were identified with a corrected $p$ value of $p<0.05$ (empirical Bayes, $\mathrm{BH}$ correction) and with a fold change of $\leq 1.0$ (table 2). Next, a comparison was made between 
Table 2. Most deregulated miRNAs and associated copy number alterations and copy number neutral loss of heterozygosity (CNN LOH)

\begin{tabular}{|c|c|c|c|c|c|c|}
\hline miRNA & Cytoband & Loss & Gain & CNN LOH & $\mathrm{p}$ adjusted ${ }^{\mathrm{a}}$ & Fold change \\
\hline miR-451 & $17 q 11.2$ & 0 & 0 & 0 & 0.000 & -5.22 \\
\hline miR-144 & $17 \mathrm{q} 11.2$ & 0 & 0 & 0 & 0.000 & -4.63 \\
\hline miR-486-5p & $8 p 11.21$ & 0 & $1 / 21$ & 0 & 0.000 & -2.67 \\
\hline miR-223 & $\mathrm{Xq} 12$ & 0 & $1 / 21$ & 4/8 females & 0.000 & -2.59 \\
\hline $\operatorname{miR}-144^{\mathrm{a}}$ & $17 \mathrm{q} 11.2$ & 0 & 0 & 0 & 0.000 & -1.86 \\
\hline miR-185 & $22 \mathrm{q} 11.21$ & 0 & $1 / 21$ & 0 & 0.000 & -1.66 \\
\hline miR-16-1 & $3 q 26.1$ & 0 & 0 & 0 & 0.000 & -1.49 \\
\hline miR-16-2 & $13 \mathrm{q} 14.3$ & 0 & 0 & 0 & & \\
\hline miR-22 & $17 \mathrm{p} 13.3$ & $2 / 21$ & 0 & 0 & 0.000 & -1.46 \\
\hline miR-1202 & $6 q 25.3$ & 0 & 0 & 0 & 0.002 & -1.37 \\
\hline miR-15b & $3 q 26.1$ & 0 & 0 & 0 & 0.000 & -1.36 \\
\hline miR-101-1 & $1 \mathrm{p} 31.3$ & 0 & 0 & 0 & 0.000 & -1.35 \\
\hline miR-101-2 & $9 \mathrm{p} 24.1$ & $4 / 21$ & 0 & $2 / 21$ & & \\
\hline miR-107 & $10 \mathrm{q} 23.31$ & 0 & 0 & 0 & 0.000 & -1.34 \\
\hline miR-148a & 7 p15.2 & $3 / 21$ & 0 & 0 & 0.000 & -1.17 \\
\hline miR-26b & $2 q 35$ & 0 & 0 & 0 & 0.001 & -1.10 \\
\hline miR-128-1 & $2 q 21.3$ & 0 & 0 & 0 & 0.025 & 1.08 \\
\hline miR-128-1 & 3 p22.3 & 0 & 0 & 0 & & \\
\hline miR-1305 & $4 q 35.1$ & 0 & $1 / 21$ & 0 & 0.001 & 1.15 \\
\hline miR-34a & $1 \mathrm{p} 36.23$ & 0 & 0 & 0 & 0.001 & 1.18 \\
\hline miR-720 & $3 \mathrm{q} 26.1$ & 0 & 0 & $1 / 21$ & 0.000 & 1.42 \\
\hline miR-155 & $21 \mathrm{q} 21.3$ & 0 & 0 & 0 & 0.000 & 1.58 \\
\hline miR-146a & $5 q 33.3$ & 0 & 0 & 0 & 0.000 & 1.75 \\
\hline miR-181b1 & $1 \mathrm{q} 31.3$ & 0 & $1 / 21$ & 0 & 0.000 & 2.84 \\
\hline miR-181b2 & $9 q 33.3$ & $1 / 21$ & $1 / 21$ & 0 & & \\
\hline miR-181a & $9 q 33.3$ & $1 / 21$ & $1 / 21$ & 0 & 0.000 & 3.52 \\
\hline
\end{tabular}

${ }^{a}$ Only one value is given for identical miRNAs having 2 distinct loci.

$B C R-A B L 1$ positive $(\mathrm{n}=4)$ and negative $(\mathrm{n}=11)$ B-cell ALL cases; T-cell ALL samples $(n=4)$ were excluded. The expression of miR-29b was slightly but still significantly higher in $B C R-A B L 1$ positive than in negative cases (table 3).

Recurrent CNAs or CNN LOH, associated with differentially expressed miRNAs, were detected at chromosomes 7, 9, 17, and X (table 2). miR-101, which has 2 distinct chromosomal loci, was downregulated in ALL with deletions at 9p24.1, the location of miR-101-2. The deletions were detected only in $B C R-A B L 1$ positive cases ( 4 out of 7 cases). In contrast, CNN LOH at the miR-101-2 locus was detected in 2 out of the $16 B C R-A B L 1$ negative cases and, noticeably, in none of the $B C R-A B L 1$ positive cases.

With the aCGH method, we identified potential tumor suppressor and oncogenes in minimal overlapping regions of loss and gain. The mRNA encoded by these genes could be deregulated by miRNAs. The predicted targets of the miRNAs, identified by us to be deregulated in adult ALL, were retrieved from 4 miRNA databases (miRanda, PicTar, miRBase, and TargetScan). Screening of these targets revealed several of the potential tumor suppressors or oncogenes (table 4).

In total, $83 \mathrm{miR}-29 \mathrm{~b}$ targets were shared by miRanda, PicTar, TargetScan, and miRBase databases. Subsequent pathway analysis showed that several pathways, such as signaling by PDGF, NCAM1 interactions, NCAM signaling for neurite out-growth, and integrin cell surface interactions, might be affected more common than expected ( $p<0.05$, table 5). For miR-101, no significant pathway was identified, although 51 common targets were found.

\section{Discussion}

By using high-resolution genome-wide analyses, we detected CNAs or CNN LOH in $90 \%$ of adult ALL cases. Our CNA findings were confirmed both with the Agilent 
244K and the Affymetrix SNP 6.0 array platforms, except for some small differences that were possibly due to probe design differences of the 2 array types. Overall, we observed that the 2 platforms perform comparable in discovering copy number alterations. However, the advantage of SNP arrays over aCGH is that SNP arrays can reveal CNN LOH [Tuna et al., 2009]. In ALL, genome-wide array studies have previously revealed submicroscopic alterations in pediatric cases [Irving et al., 2005; Kuiper et al., 2007; Mullighan et al., 2007; Kuchinskaya et al, 2008; Rabin et al., 2008; Bungaro et al., 2009], in cases from all ages [Strefford et al., 2007; Mullighan et al., 2008; Simons et al., 2011], and in adults [Matteucci et al., 2010; Nowak et al., 2010; Okamoto et al., 2010]. Regarding our ALL study, we detected several gene deletions, previously reported by others; BTG1 at 12q22 [Kuiper et al., 2007; Mullighan et al., 2007, 2008; Okamoto et al., 2010; Lundin et al., 2012], BTLA at 3q13.2 [Mullighan et al., 2007], $M L L$ at 11q23 [Harbott et al., 1998; Takeuchi et al.,1999], as well as $C D K N 2 A, C D K N 2 B, J A K 2$, and PAX5 at 9p [Irving et al., 2005; Kuiper et al., 2007; Mullighan et al., 2007; Usvasalo et al., 2010a]. In addition, CNN LOH at 9p was detected in 3 of 21 cases. Recurrent gains were less frequent than deletions. Gains/amplifications at chromosome 8 containing MYC, observed in 3 patients in our study, are recurrent but not common alterations in ALL [Okamoto et al., 2010]. Similarly, we detected some novel candidate genes in ALL at minimal recurrently deleted regions, namely RERE at $1 \mathrm{p} 36.23, E 2 F 4$ at $16 \mathrm{q} 22.1$, and TCF12 at 15q21.3 whose role in adult ALL, thus far, remains unclear.

Despite different cytogenetic alterations characterizing adult and pediatric ALL, differences in submicroscopic copy number alterations have not been detected, although in adults, chromosomes 7 and 17 are more frequently altered [Okamoto et al., 2010]. In our cohort we detected changes at chromosome 7 in 11/21 cases. Whole chromosome 7 was deleted in 2 cases and $7 p$ in 1 case, whereas 1 patient had a gain at 7q22.1q22.2. Deletions of 7 p12.2 containing IKZF1 were detected in 11/21 samples (52\%).

In the Agilent 244K CGH microarray, 10 oligoprobes cover the whole IKZF1 gene and, according to Agilent, the spatial resolution of the array is on average $6.4 \mathrm{~kb}$. The Affymetrix SNP 6.0 microarray has been shown to be more sensitive for the detection of IKZF1 deletions, as seen in our previous study [Usvasalo et al., 2010a] where deletions $<35 \mathrm{~kb}$ could be detected. It is, however, possible that the smallest deletions remain invisible, even though the SNP array most probably covers the vast ma-
Table 3. miR-29b expression values in $B C R-A B L 1$ positive versus negative patients

\begin{tabular}{lll}
\hline & Patient & miR-29b expression values \\
\hline BCR-ABL1 positive & AA212 & 8.7 \\
& AA216 & 9.2 \\
& AA207 & 8.33 \\
& AA222 & 9.21 \\
\hline BCR-ABL1 negative & AA210 & 7.91 \\
& AA215 & 8.49 \\
& AA206 & 7.64 \\
& AA208 & 7.94 \\
& AA224 & 7.51 \\
& AA202 & 8.29 \\
& AA204 & 7.74 \\
& AA219 & 7.53 \\
& AA201 & 7.82 \\
AA205 & 7.75 \\
\hline poljusted & AA220 & 7.72 \\
\hline Fold change & & 0.045354 \\
\hline
\end{tabular}

Table 4. Selected candidate genes located in the minimal overlapping regions and differentially expressed miRNAs that, according to at least 2 of the 4 analyzed target prediction databases (miRanda, PicTar, miRBase, TargetScan), could be translational regulators of the mRNA coded by these genes

\begin{tabular}{lll}
\hline $\begin{array}{l}\text { Chromosomal } \\
\text { location }\end{array}$ & Gene symbol & Potential regulator miRNAs \\
\hline 1p36.23 & RERE & miR-128, miR-185 \\
3q13.2 & BTLA & miR-181b \\
7p12.2 & DDC & - \\
7p12.2 & IKZF1 & - \\
8q24.13q24.3 & MYC & - \\
9p13 & PAX5 & - \\
9p21.3 & CDKN2A & - \\
9p21.3 & CDKN2B & miR-451 \\
9p24.1 & JAK2 & miR-155, miR-144, miR-101 \\
$11 \mathrm{q} .23$ & MLL & miR-148a, miR-128 \\
12p13.2 & $E T V 6$ & miR-181a, miR-181b \\
$12 q 21.33$ & BTG1 & miR-22 \\
$15 q 21.3$ & TCF12 & miR-34a, miR-185 \\
$16 q 22.1$ & $E 2 F 4$ & - \\
$17 p 13.1$ & TP53 & miR-22 \\
$17 q 11$ & NF1 & -
\end{tabular}

Downregulated miRNAs are shown in normal font and upregulated miRNAs in bold. 
Table 5. Over-represented pathways that include miR-29b target genes

\begin{tabular}{lll}
\hline Pathway & p value & Database \\
\hline Syndecan-1-mediated signaling events & 0.000000 & PID \\
Betal integrin cell surface interactions & 0.000000 & PID \\
Protein digestion and absorption - Homo sapiens (human) & 0.000001 & KEGG \\
Integrins in angiogenesis & 0.000002 & PID \\
ECM-receptor interaction - Homo sapiens (human) & 0.000012 & KEGG \\
NCAM signaling for neurite out-growth & 0.000040 & Reactome \\
NCAM1 interactions & 0.000047 & KEGG \\
Amoebiasis - Homo sapiens (human) & 0.000404 & KEGG \\
Focal adhesion - Homo sapiens (human) & 0.000469 & Reactome \\
Signaling by PDGF & 0.000782 & PID \\
Beta3 integrin cell surface interactions & 0.007013 & Wikipathways \\
Focal adhesion & 0.007221 & Reactome \\
Integrin cell surface interactions & 0.007541 & \\
\hline
\end{tabular}

PID = http://pid.nci.nih.gov/; KEGG = http://www.genome.jp/kegg/; Reactome = http://www.reactome.org/; Wikipathways = http://wikipathways.org/.

jority of $I K Z F 1$ deletions. Comparison of $I K Z F 1$ deletions with the $B C R-A B L 1$ status revealed that IKZF1 deletions were present in $6 / 7$ (86\%) of the $B C R-A B L 1$ positive cases, but only in $5 / 14(36 \%)$ in $B C R-A B L 1$ negative cases. Of note, previous studies have shown that deletions of $I K Z F 1$ indicate poor prognosis in ALL [Mullighan et al., 2009; Waanders et al., 2011] and they are involved in $29-84 \%$ in $B C R-A B L 1$ positive ALL patients, while in $B C R-A B L 1$ negative patients the corresponding percentage is significantly lower [Mullighan et al., 2008; Okamoto et al., 2010].

Like other studies, we also detected several aberrations at chromosome 17 , specifically deletions and amplifications, as well as in 1 case also a large CNN LOH of $39 \mathrm{Mb}$ in size. Similarly, we detected large deletions at $17 \mathrm{p}$, including TP53. As for NF1 deletions at 17q11.2, they have been previously detected by the aCGH method in $3 \%$ of pediatric T-cell ALL [Balgobind et al., 2008] and in 11\% of adult T-cell ALL [Matteucci et al., 2010]. In our study, the $N F 1$ tumor suppressor at 17q11.2 was deleted in 2 patients with T-cell ALL and in 1 patient with B-cell ALL.

We compared the miRNA expression of FFPE bone marrow core biopsy ALL samples with the expression of bone marrow aspirate smear samples from healthy individuals. Bone marrow smears and core biopsies may have some differences in the cellular contents in that core biopsies can, for example, contain more fat and fibrotic elements. The proportions of different hematopoietic cells/ cell lineages are, however, thought to be similar. A very important benefit is that both sample types, i.e. bone marrow smears and core biopsies, allow the evaluation of cellular elements before miRNA extraction.

As normal bone marrow contains numerous cellular components, some of the differences detected in our core biopsy study may be explained by the differences in the normal expression differences between other cell lineages than those from which ALL originates. The same is true for most cancer-related expression analyses. Actually, this problem remains even in the case that bone marrow stem cells are used in the analysis. As yet, we cannot determine whether these stem cells are malignant or not.

Our study revealed 22 differentially expressed miRNAs in ALL versus control samples. In concordance with previous reports, mir-181a and miR-181b were upregulated while miR-223 was downregulated [Schotte et al., 2009; Zhang et al., 2009]. In accordance with Mi et al. [2007], no altered expressions were observed in miR-1281 or miR-128-2, whereas miR-146a was upregulated only in our study. This miRNA has been associated with a poor outcome in ALL and acute myeloid leukemia (AML) [Wang et al., 2010].

In some patients, differentially expressed miRNAs were located in recurrently lost genomic regions. For example, the highly downregulated miR-22 and miR-148a were detected in the recurrently lost areas of chromosomes 7 and 17, while the downregulated miR-223 was located in the recurrent $\mathrm{CNN} \mathrm{LOH}$ region of chromosome Xq. Of note, these miRNAs were also deregulated in patients who did not exhibit copy number alterations 
or LOH of the particular miRNA loci. Thus, in addition to CNAs or CNN LOH, other mechanisms seem to be at work in miRNA expression regulation. Indeed, miR-22, which was downregulated in our analysis, is sometimes epigenetically silenced through histone modification in ALL [Li et al., 2010]. Besides, another miRNA downregulated in our study, miR-148a, is reportedly silenced in metastatic cancer by DNA methylation [Lujambio et al., 2008]. Mutations or SNPs in miRNAs or in their targets may entail other possible mechanisms that cause changes in miRNA-associated gene regulation [Ryan et al., 2010].

We analyzed the miRNA expression differences between $B C R-A B L 1$ positive $(\mathrm{n}=4)$ and negative $(\mathrm{n}=11)$ $\mathrm{B}$-cell ALL. One previously suggested regulator of $B C R$ $A B L 1$ expression is miR-203. Downregulated expression of miR-203, affected by deletions and methylation changes, has been described in $B C R-A B L 1$ positive CML and pediatric ALL cases [Bueno et al., 2008]. We did not, however, detect any deregulation of miR-203 among our adult ALL cases, which may be due to the fact that our miRNA analysis comprised a relatively low number $(\mathrm{n}=$ 4) of $B C R-A B L 1$ positive cases or because of our selection of adult patients. Instead, in $B C R-A B L 1$ positive cases we detected a slight, but statistically significant, increase in the expression of miR-29b. This association is a novel finding, although other cancer-related studies have reported both upregulation and downregulation of miR-29 and have suggested a role as both tumor suppressor and oncogene, depending on the cellular context [Pekarsky et al., 2006; Fabbri et al., 2007; Mott et al., 2007; Garzon et al., 2009; Gebeshuber et al., 2009; Han et al., 2010; Santanam et al., 2010]. The miRNA target prediction databases enumerate hundreds of targets for miR-29b. Actually, we compared the targets listed in 4 different databases and found 83 targets that were shared. A pathway analysis of these genes showed over-representation of PDGF, NCAM, and integrin cell surface interaction signaling pathways, suggesting that miR-29b might be involved in regulation of these pathways. Notably, miR-29 has been shown to regulate MCL1 in cholangiocarcinoma cell lines [Mott et al., 2007], TCL1 in chronic lymphocytic leukemia (CLL) [Pekarsky et al., 2006], as well as DNMT3A and DNMT3B in lung cancer and AML [Fabbri et al., 2007; Garzon et al., 2009]. In metastatic breast cancer, upregulated miR-29 reduces expression of tristetraprolin [Gebeshuber et al., 2009], while in CLL PXDN has been suggested to be a candidate tumor suppressor regulated by miR-29 [Santanam et al., 2010]. In addition, the expression of miR-29 reportedly causes CLL and
AML in mouse models [Han et al., 2010; Santanam et al., 2010]. miR-29 has 2 forms with slightly differing sequences, miR-29a and -b. miR-29a is located at 7q32.3, while miR-29b is encoded by 2 different loci, miR-29b-1 at $7 \mathrm{q} 32.3$ and miR29b-2 at $1 \mathrm{q} 32.2$. In our study there were no differences in copy number of these loci between $B C R-A B L 1$ positive and negative cases, indicating that other changes than copy number alterations do affect the expression differences.

Similarly, our study revealed another interesting change possibly associated with $B C R-A B L 1$, namely the deletion of the miR-101-2 locus. miR-101 was downregulated in our adult ALL cases, and 1 of the 2 loci, 9p24.1 containing miR-101-2, was recurrently deleted or affected by CNN LOH. miR-101-2 deletions were detected in 4 out of $7 B C R-A B L 1$ positive patients and in none of the $B C R$ $A B L 1$ negative ones. $\mathrm{CNN} \mathrm{LOH}$, however, was detected in 2 out of $14 B C R-A B L 1$ negative patients and in none of the $B C R-A B L 1$ positive cases. We speculate that in $B C R-A B L$ positive cases downregulation of miR-101-2 (by deletions) may have an oncogenic influence, whereas in $B C R$ $A B L$ negative cases (where CNN LOH was present) a homozygous activating mutation in miR-101-2 may be present which causes high enough expression to dysregulate or inhibit a suppressor-type gene.

In conclusion, we detected copy number changes and CNN LOH regions in adult ALL with candidate genes or known cancer genes and identified 22 deregulated miRNAs of which miR-22, miR-148a, miR-101-2, and miR-223 were located in recurrent regions of CNAs or CNN LOH. miRNA expression analysis indicated that $B C R-A B L$ positive cases exhibited elevated expression of miR-29b and recurrent deletions of miR-101-2 in 9p24. In $B C R-A B L$ negative cases, miR-101-2 at 9p24.1 was detected in 2 cases with $\mathrm{CNN} \mathrm{LOH}$ areas. Yet, to confirm these novel findings, further studies are needed.

\section{Acknowledgements}

This work was supported by the Special State Subsidies for Research and Training of Helsinki University Central Hospital (EVO), the Finnish Cancer Organizations, and the Nona and Kullervo Väre Foundation. 


\section{References}

Armstrong SA, Look AT: Molecular genetics of Griffiths-Jones S, Saini HK, van Dongen S, Enacute lymphoblastic leukemia. J Clin Oncol 23:6306-6315 (2005).

Balgobind BV, Van Vlierberghe P, van den Ouweland AM, Beverloo HB, Terlouw-Kromosoeto JN, et al: Leukemia-associated NF1 inactivation in patients with pediatric T-ALL and AML lacking evidence for neurofibromatosis. Blood 111:4322-4328 (2008).

Baudis M, Cleary ML: Progenetix.net: an online repository for molecular cytogenetic aberration data. Bioinformatics 17: 228-1229 (2001).

Borze I, Guled M, Musse S, Raunio A, Elonen E, et al: MicroRNA microarrays on archive bone marrow core biopsies of leukemias method validation. Leuk Res 35:188-195 (2011).

-Bueno MJ, Perez de Castro I, Gomez de Cedron M, Santos J, Calin GA, et al: Genetic and epigenetic silencing of microRNA-203 enhances $A B L 1$ and $B C R-A B L 1$ oncogene expression. Cancer Cell 13:496-506 (2008).

-Bungaro S, Dell'Orto MC, Zangrando A, Basso $\mathrm{D}$, Gorletta $\mathrm{T}$, et al: Integration of genomic and gene expression data of childhood ALL without known aberrations identifies subgroups with specific genetic hallmarks. Genes Chromosomes Cancer 48:22-38 (2009).

Croce CM: Causes and consequences of microRNA dysregulation in cancer. Nat Rev Genet 10:704-714 (2009).

Dombret H, Gabert J, Boiron JM, Rigal-Huguet F, Blaise D, et al: Outcome of treatment in adults with Philadelphia chromosome-positive acute lymphoblastic leukemia - results of the prospective multicenter LALA-94 trial. Blood 100:2357-2366 (2002).

-Enright AJ, John B, Gaul U, Tuschl T, Sander C, Marks DS: MicroRNA targets in Drosophila. Genome Biol 5:R1 (2003).

Fabbri M, Garzon R, Cimmino A, Liu Z, Zanesi $\mathrm{N}$, et al: MicroRNA-29 family reverts aberrant methylation in lung cancer by targeting DNA methyltransferases $3 \mathrm{~A}$ and $3 \mathrm{~B}$. Proc Natl Acad Sci USA 104:15805-15810 (2007).

- Fullmer A, Kantarjian H, Cortes J, Jabbour E: New developments in the treatment of chronic myeloid leukemia and Philadelphiapositive acute lymphoblastic leukemia. Leuk Lymphoma 52 Suppl 1:81-91 (2011).

-Garzon R, Liu S, Fabbri M, Liu Z, Heaphy CE, et al: MicroRNA-29b induces global DNA hypomethylation and tumor suppressor gene reexpression in acute myeloid leukemia by targeting directly DNMT3A and $3 B$ and indirectly DNMT1. Blood 113:6411-6418 (2009).

-Gebeshuber CA, Zatloukal K, Martinez J: miR$29 a$ suppresses tristetraprolin, which is a regulator of epithelial polarity and metastasis. EMBO Rep 10:400-405 (2009). right AJ: miRBase: tools for microRNA genomics. Nucleic Acids Res 36:D154-D158 (2008).

Han YC, Park CY, Bhagat G, Zhang J, Wang Y, et al: microRNA-29a induces aberrant self-renewal capacity in hematopoietic progenitors, biased myeloid development, and acute myeloid leukemia. J Exp Med 207:475-489 (2010).

Harbott J, Mancini M, Verellen-Dumoulin C, Moorman AV, Secker-Walker LM: Hematological malignancies with a deletion of 11q23: cytogenetic and clinical aspects. European 11q23 workshop participants. Leuke-

Irving JA, Bloodworth L, Bown NP, Case MC, Hogarth LA, Hall AG: Loss of heterozygosity in childhood acute lymphoblastic leukemia detected by genome-wide microarray single nucleotide polymorphism analysis. Cancer Res 65:3053-3058 (2005).

-Kamburov A, Wierling C, Lehrach H, Herwig R: ConsensusPathDB - a database for integrating human functional interaction networks. Nucleic Acids Res 37:D623-628 (2009).

Krek A, Grun D, Poy MN, Wolf R, Rosenberg L, et al: Combinatorial microRNA target predictions. Nat Genet 37:495-500 (2005).

Kuchinskaya E, Heyman M, Nordgren A, Schoumans J, Staaf J, et al: Array-CGH reveals hidden gene dose changes in children with acute lymphoblastic leukaemia and a normal or failed karyotype by G-banding. Br J Haematol 140:572-577 (2008).

Kuiper RP, Schoenmakers EF, van Reijmersdal SV, Hehir-Kwa JY, van Kessel AG, et al: High-resolution genomic profiling of childhood ALL reveals novel recurrent genetic lesions affecting pathways involved in lymphocyte differentiation and cell cycle progression. Leukemia 21:1258-1266 (2007).

Lewis BP, Burge CB, Bartel DP: Conserved seed pairing, often flanked by adenosines, indicates that thousands of human genes are microRNA targets. Cell 120:15-20 (2005).

Li X, Liu J, Zhou R, Huang S, Huang S, Chen XM: Gene silencing of MIR22 in acute lymphoblastic leukaemia involves histone modifications independent of promoter DNA methylation. Br J Haematol 148:69-79 (2010). Lamb J, et al: MicroRNA expression profiles classify human cancers. Nature 435:834-838 (2005).

Lujambio A, Calin GA, Villanueva A, Ropero S, Sánchez-Céspedes $M$, et al: A microRNA DNA methylation signature for human cancer metastasis. Proc Natl Acad Sci USA 105: 13556-13561 (2008).

Lundin C, Hjorth L, Behrendtz M, Nordgren A, Palmqvist L, et al: High frequency of BTG1 deletions in acute lymphoblastic leukemia in children with Down syndrome. Genes Chromosomes Cancer 51:196-206 (2012). mia 12:823-827 (1998).

Lu J, Getz G, Miska EA, Alvarez-Saavedra E,
Matteucci C, Barba G, Varasano E, Vitale A, Mancini M, et al: Rescue of genomic information in adult acute lymphoblastic leukaemia (ALL) with normal/failed cytogenetics: a GIMEMA centralized biological study. $\mathrm{Br}$ J Haematol 149:70-78 (2010).

Mi S, Lu J, Sun M, Li Z, Zhang H, et al: MicroRNA expression signatures accurately discriminate acute lymphoblastic leukemia from acute myeloid leukemia. Proc Natl Acad Sci USA 104:19971-19976 (2007).

Moorman AV, Chilton L, Wilkinson J, Ensor HM, Bown N, Proctor SJ: A populationbased cytogenetic study of adults with acute lymphoblastic leukemia. Blood 115:206-214 (2010).

Mott JL, Kobayashi S, Bronk SF, Gores GJ: mir29 regulates $\mathrm{Mcl}-1$ protein expression and apoptosis. Oncogene 26:6133-6140 (2007).

Mullighan CG, Goorha S, Radtke I, Miller CB, Coustan-Smith E, et al: Genome-wide analysis of genetic alterations in acute lymphoblastic leukaemia. Nature 446:758-764 (2007).

Mullighan CG, Miller CB, Radtke I, Phillips LA, Dalton J, et al: BCR-ABL1 lymphoblastic leukaemia is characterized by the deletion of Ikaros. Nature 453:110-114 (2008).

-Mullighan CG, Su X, Zhang J, Radtke I, Phillips LA, et al: Deletion of $I K Z F 1$ and prognosis in acute lymphoblastic leukemia. N Engl J Med 360:470-480 (2009).

Nowak NJ, Sait SN, Zeidan A, Deeb G, Gaile D, et al: Recurrent deletion of 9q34 in adult normal karyotype precursor B-cell acute lymphoblastic leukemia. Cancer Genet Cytogenet 199:15-20 (2010).

> Okamoto R, Ogawa S, Nowak D, Kawamata N, Akagi T, et al: Genomic profiling of adult acute lymphoblastic leukemia by single nucleotide polymorphism oligonucleotide microarray and comparison to pediatric acute lymphoblastic leukemia. Haematologica 95: 1481-1488 (2010).

- Pekarsky Y, Santanam U, Cimmino A, Palamarchuk A, Efanov A, et al: Tcl1 expression in chronic lymphocytic leukemia is regulated by $m i R-29$ and $m i R-181$. Cancer Res 66: 11590-11593 (2006).

Pui CH, Evans WE: Treatment of acute lymphoblastic leukemia. N Engl J Med 354:166-178 (2006).

Rabin KR, Man TK, Yu A, Folsom MR, Zhao YJ, et al: Clinical utility of array comparative genomic hybridization for detection of chromosomal abnormalities in pediatric acute lymphoblastic leukemia. Pediatr Blood Cancer 51:171-177 (2008).

Ryan BM, Robles AI, Harris CC: Genetic variation in microRNA networks: the implications for cancer research. Nat Rev Cancer 10 : 389-402 (2010). 
Santanam U, Zanesi N, Efanov A, Costinean S, Palamarchuk A, et al: Chronic lymphocytic leukemia modeled in mouse by targeted $m i R$ 29 expression. Proc Natl Acad Sci USA 107: 12210-12215 (2010).

Scheinin I, Myllykangas S, Borze I, Böhling T, Knuutila S, Saharinen J: CanGEM: mining gene copy number changes in cancer. Nucleic Acids Res 36(Database issue):D830-835 (2008).

- Schotte D, Chau JC, Sylvester G, Liu G, Chen C, et al: Identification of new microRNA genes and aberrant microRNA profiles in childhood acute lymphoblastic leukemia. Leukemia 23:313-322 (2009).

-Simons A, Stevens-Kroef M, El Idrissi-Zaynoun N, van Gessel S, Weghuis DO, et al: Microarray-based genomic profiling as a diagnostic tool in acute lymphoblastic leukemia. Genes Chromosomes Cancer 50: 969-981 (2011).

Smyth GK: Linear models and empirical Bayes methods for assessing differential expression in microarray experiments. Stat App Genet Mol Biol 3:Article3 (2004).
- Strefford JC, Worley H, Barber K, Wright S, Stewart AR, et al: Genome complexity in acute lymphoblastic leukemia is revealed by array-based comparative genomic hybridization. Oncogene 26:4306-4318 (2007).

Takeuchi S, Cho SK, Seriu T, Koike M, Bartram $\mathrm{CR}$, et al: Identification of three distinct regions of deletion on the long arm of chromosome 11 in childhood acute lymphoblastic leukemia. Oncogene 18:7387-7388 (1999).

Tuna M, Knuutila S, Mills GB: Uniparental disomy in cancer. Trends Mol Med 15:120-128 (2009).

- Usvasalo A, Savola S, Raty R, Vettenranta K, Harila-Saari A, et al: CDKN2A deletions in acute lymphoblastic leukemia of adolescents and young adults: an array CGH study. Leuk Res 32:1228-1235 (2008).

-Usvasalo A, Räty R, Harila-Saari A, Koistinen P, Savolainen ER, et al: Acute lymphoblastic leukemias with normal karyotypes are not without genomic aberrations. Cancer Genet Cytogenet 192:10-17 (2009).

-Usvasalo A, Ninomiya S, Räty R, Hollmén J, Saarinen-Pihkala UM, et al: Focal 9p instability in hematologic neoplasias revealed by comparative genomic hybridization and singlenucleotide polymorphism microarray analyses. Genes Chromosomes Cancer 49:309318 (2010a).
Usvasalo A, Elonen E, Saarinen-Pihkala UM, Räty R, Harila-Saari A, et al: Prognostic classification of patients with acute lymphoblastic leukemia by using gene copy number profiles identified from array-based comparative genomic hybridization data. Leuk Res 34:1476-1482 (2010b).

-Waanders E, van der Velden VH, van der Schoot CE, van Leeuwen FN, van Reijmersdal SV, et al: Integrated use of minimal residual disease classification and $I K Z F 1$ alteration status accurately predicts $79 \%$ of relapses in pediatric acute lymphoblastic leukemia. Leukemia 25:254-258 (2011).

Wang Y, Li Z, He C, Wang D, Yuan X, et al: MicroRNAs expression signatures are associated with lineage and survival in acute leukemias. Blood Cells Mol Dis 44:191-197 (2010).

Zhang $\mathrm{H}$, Yang JH, Zheng YS, Zhang P, Chen X, et al: Genome-wide analysis of small RNA and novel microRNA discovery in human acute lymphoblastic leukemia based on extensive sequencing approach. PLoS One 4:e6849 (2009). 